\title{
SECAGEM DE POLPA DE CAQUI PELO MÉTODO DE CAMADA DE ESPUMA
}

\author{
P. R. PÊ* , G. G. CARNEIRO, F. R. PÊ, D. S. DE CASTRO, D. R. S. SILVA e L. F. MARQUES \\ Universidade Federal de Campina Grande \\ patriciarodriguespe@yahoo.com.br*
}

Artigo submetido em setembro/2014 e aceito em março/2016

DOI: $10.15628 /$ holos.2016.2444

\section{RESUMO}

Esta pesquisa teve por objetivo desidratar diferentes formulações de polpa de caqui em camada de espuma na temperatura de 70 o $C$ através do ajuste de modelos matemáticos de secagem aos dados experimentais. Foi utilizado polpa de caqui, comercializada no município de Campina Grande - PB preparada em três diferentes formulações: 1- emulsificante, 2 - liga neutra, 3 emulsificante e liga neutra. A mistura foi disposta em bandejas e levada para secagem em estufa de ar forçado a $70{ }^{\circ} \mathrm{C}$. Os dados da secagem foram ajustados aos modelos: Cavalcanti Mata, Logarítimico, Page e Midilli e Kucuk, verificando que todos os modelos utilizados ajustaram-se satisfatoriamente aos dados experimentais com coeficientes de determinações superiores a 0,96 e desvios quadráticos médios inferiores a 0,02 , porém o modelo de Cavalcanti Mata demonstra uma superioridade por apresentar os maiores valores de $\mathrm{R}^{2} \mathrm{e}$ menores valores de DQM.

PALAVRAS-CHAVE: foam-mat, cinética, modelagem matemática.

\section{DRYING OF PERSIMMON PULP BY THE METHOD OF THE FOAM LAYER}

\begin{abstract}
This research aimed to dehydrate different formulations of persimmon pulp in the foam layer at a temperature of $70^{\circ} \mathrm{C}$ by adjusting drying mathematical models to experimental data. Was used persimmon pulp, sold in Campina Grande - PB prepared in three different formulations: 1 emulsifier, 2 - League neutral, 3 - neutral emulsifier and league. The mixture was prepared in trays and taken to drying in a $70^{\circ} \mathrm{C}$ forced air. The drying data
\end{abstract}

were fitted to models: Mata Cavalcanti, logarithmic, and Page Midilli and Kucuk, verifying that all models used adjusted satisfactorily to the experimental data with coefficients of determination greater than 0,96 and less than mean squared deviations 0,02 , but the model of Cavalcanti Mata demonstrates superiority to present the highest values of $R^{2}$ and lower values of DQM.

KEYWORDS: foam-mat, kinetics, mathematical modeling. 


\section{INTRODUÇÃO}

Quando avaliamos a demanda por informações e tecnologia nos últimos anos, fica claro que a fruticultura, dentre as várias atividades do agronegócio, é uma das mais evidentes e propagadas alternativas de negócio no país atualmente (Vilela, 2011).

Tibola \& Fachinello (2004) afirmam que, vem ocorrendo uma maior conscientização por parte dos consumidores sobre a importância da seleção de alimentos saudáveis para prevenção de doenças e na melhoria da qualidade de vida, já que no âmbito dos alimentos preferidos ou recomendados, as frutas se destacam seja como fonte de alimento ou na prevenção de doenças.

O interesse pela cultura do caquizeiro é justificado por uma extraordinária adaptação às condições edafoclimáticas de algumas regiões brasileiras e pelas características do fruto, que apresenta excelente sabor, aparência atraente e elevada qualidade nutricional, constituindo uma boa fonte de fibras, carboidratos (Vasconcelos, 2000), vitaminas e sais minerais (Wright \& Kader, 1997). Tais particularidades garantem a boa aceitação do fruto no mercado (Simão, 1998).

A cultura do caqui vem ganhando importância no Brasil, tanto pela área plantada quanto pelo aumento da produção, que tem propulsionado o aumento da oferta do produto para o mercado interno, e consequentemente, impulsionando os produtores para que parte da produção seja exportada. De acordo com dados da FAO (Food and Agriculture Organization of the United Nations), a produção mundial de caqui, em 2007, foi de 3,3 milhões de toneladas. Sendo que a China, maior produtor, produziu cerca de 2,3 milhões de toneladas, seguida da República da Coréia com 345 mil toneladas, Japão com 240 mil toneladas, e Brasil, ocupando o quarto lugar no ranking mundial, produzindo cerca de 169 mil toneladas.

As regiões Sul e Sudeste são as maiores produtoras, sendo lideradas pelo estado de São Paulo. De acordo com dados do IEA (Instituto de Economia Agrícola), no ano de 2007, apenas o município de Mogi das Cruzes, estado de São Paulo, contribuiu com a produção de 49,7 mil toneladas de caqui.

No entanto, sua alta perecibilidade tem provocado grandes perdas do fruto durante o armazenamento que se devem, em maior importância, ao excesso de maturação, perda de firmeza, podridões e à incidência de escurecimento da casca dos frutos. Segundo Lemos et al. (2008), as frutas e hortaliças in natura são altamente perecíveis e vários são os problemas relacionados à sua conservação, que vêm desde o momento em que são colhidas, quando se dá início a uma série de processos que influenciam na qualidade do produto e nas suas consequentes avarias, antes que o mesmo chegue ao consumidor.

O potencial de conservação de um fruto está diretamente relacionado, não só com o manejo adequado após a colheita, mas também, com as condições climáticas durante a produção e com as práticas culturais adotadas (Chitarra \& Chitarra, 2005). Desta forma, manejos inadequados na colheita e pós-colheita aceleram os processos de senescência, afetando sensivelmente a qualidade e limitando ainda mais o período de comercialização.

Estudos referentes ao processo de desenvolvimento de frutos e sementes constituem aspectos de grande importância para a implantação de estratégias de colheita, como também para 
se estabelecer técnicas adequadas de armazenamento pós-colheita, capazes de aumentar a vida útil, visando um melhor aproveitamento do potencial de comercialização do fruto.

De acordo com Resende et al. (2008), a secagem é uma das mais antigas e usuais operações unitárias encontradas para assegurar a qualidade e estabilidade dos produtos agrícolas considerando que a diminuição da quantidade de água do material reduz a atividade biológica e as mudanças químicas e físicas que ocorrem durante o armazenamento.

Dentre as técnicas de secagens empregadas para a manutenção da qualidade pós-colheita, os produtos alimentícios em pó são cada vez mais utilizados pela indústria nacional de alimentos, uma vez que eles reduzem significativamente os custos de certas operações como embalagens, transporte, armazenamento e conservação que elevam o valor comercial do produto (Costa et al., 2003).

O processo de secagem em camada de espuma (Foam Mat) consiste em uma técnica de conservação, no qual a pasta ou suspensão é transformada numa espuma estável, por meio de batedura e incorporação de ar ou outro gás. Esta espuma é submetida à secagem utilizando ar aquecido, até o ponto em que impeça o crescimento de micro-organismos, reações químicas e/ou enzimáticas, utilizando aditivos, onde ocorre a desintegração da massa seca em escamas e, finalmente a obtenção do pó (Gurjão, 2006 \& Bastos et al., 2005).

\section{OBJETIVOS}

Este trabalho foi realizado com o objetivo de desidratar diferentes formulações de polpa de caqui em camada de espuma na temperatura de $70 \stackrel{\circ}{ } \mathrm{C}$, e de estudar o ajuste de modelos matemáticos de secagem aos dados experimentais.

\section{MATERIAL E MÉTODOS}

O presente trabalho foi conduzido no Laboratório de Armazenamento e Processamento de Produtos Agrícolas (LAPPA) da Unidade Acadêmica de Engenharia Agrícola da Universidade Federal de Campina Grande - UFCG, localizada no município de Campina Grande, PB.

Utilizou-se como matéria-prima frutos de caqui (Diospyros kaki, Linn) adquirido na Empresa Paraibana de Abastecimento e Serviços Agrícolas central de abastecimento (EMPASA), em Campina Grande, PB.

A desidratação em camada de espuma (foam-mat) deu-se, depois de estabelecida, experimentalmente três formulações: Formulação 1, composta de polpa de caqui e um emulsificante (produto a base de monoglicerideos destilados, monoesteatato de polisorbato 60); Formulação 2 , composta de polpa caqui e liga neutra; Formulação 3, composta de polpa de caqui, liga neutra e um emulsificante, utilizadas como dispersante e promotor de espuma, obtida por homogeneização desses com a polpa em agitador doméstico, até formar uma espuma com característica adequadas à secagem, o que foi alçando em um tempo de 30 minutos de batimento, seguindo as etapas do fluxograma da Figura 1.

A espuma foi espalhada sobre bandejas de aço inoxidável em uma camada média de 1,0 $\mathrm{cm}$, a qual foi levada para desidratação em estufa com circulação forçada de ar na temperatura de 
70 ㄷ. O produto desidratado foi retirado das bandejas e triturado em multiprocessador doméstico, para obtenção do produto finamente pulverizado.

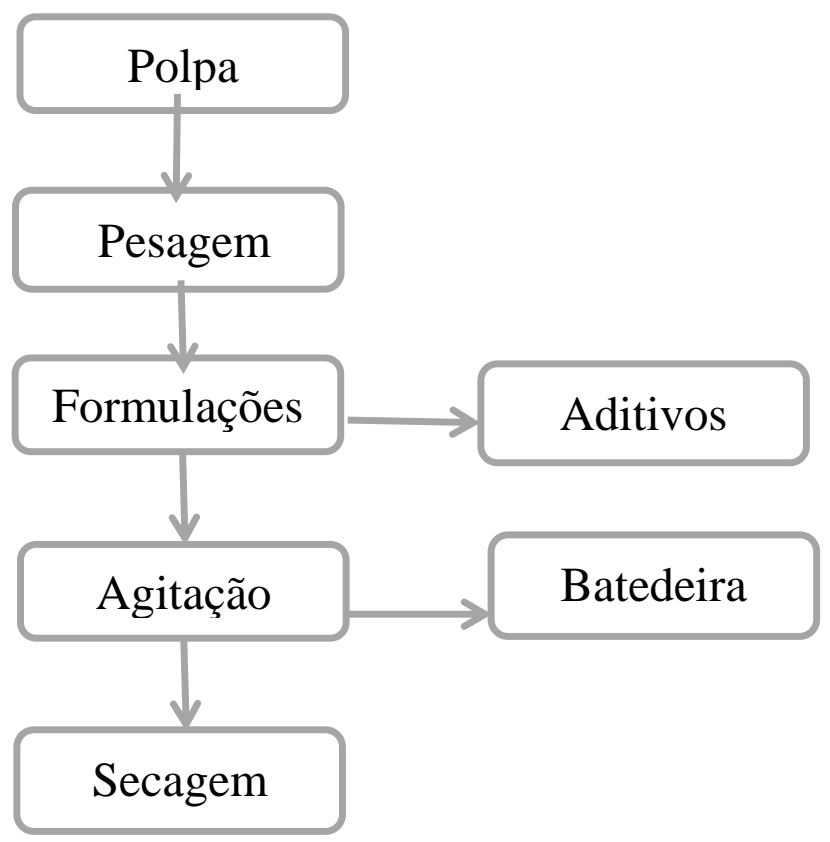

Figura 1. Fluxograma das etapas para a secagem em camada de espuma da polpa de caqui Cinética de secagem

Os dados da cinética de secagem foram obtidos pesando-se as bandejas com aproximadamente $160 \mathrm{~g}$ da amostra formulada, durante as secagens, até peso constante, em intervalos regulares. Com os dados experimentais da secagem foram calculados os valores da razão de umidade (Equação 1), e construídas as curvas de cinéticas de secagem.

$$
R U=\frac{U-U_{e}}{U_{0}-U_{e}}
$$

$\mathrm{RU}$ - razão de umidade (adimensional),

$\mathrm{U}$ - teor de umidade "absoluta" (base seca),

$U_{e}$ - teor de umidade de equilíbrio (base seca),

$\mathrm{U}_{\mathrm{o}}$ - teor de umidade inicial (base seca).

Os modelos matemáticos de Cavalcanti Mata, Page, Logarítmico e Midilli apresentados na Tabela 1, foram ajustados aos valores experimentais das cinéticas de secagem utilizando-se o programa computacional STATISTICA, versão 5.0.

Tabela 1 - Modelos matemáticos aplicados aos dados de secagem

\begin{tabular}{ccc}
\hline Modelo & Equação & Referência \\
\hline Cavalcanti Mata & $R U=a_{1} \exp \left(b t^{a_{2}}\right)+a_{3} \exp \left(b t^{a_{4}}\right)+a_{5}$ & CARVALHO et al. (2007) \\
Page & $R U=\exp \left(-K \cdot t^{n}\right)$ & GONELI et al. (2014) \\
Logarítmico & $R U=a \cdot \exp (-K \cdot t)+c$ & AKPINAR (2006) \\
Midilli & $R U=a \cdot \exp \left(-K \cdot t^{n}\right)+b \cdot t$ & CORRÊA et al. (2007)
\end{tabular}

$\mathrm{Ru}$ - razão de umidade; $a, a_{1}, a_{2}, a_{3}, a_{4}, a_{5}, b, n$ - parâmetros da equação; $t$ - tempo (min); $k$ - constante da equação ( ${ }^{-}$ $\left.{ }^{1}\right)$ 
Para avaliar qual modelo produziu o melhor ajuste foram utilizados como parâmetros o coeficiente de determinação $\left(R^{2}\right)$ e o desvio quadrático médio (Equação 2).

$$
D Q M=\sqrt{\frac{\sum\left(R U_{\text {pred }} R U_{\text {exp }}\right)^{2}}{n}}
$$

onde,

DQM - desvio quadrático médio,

$\mathrm{R} U_{\text {pred }}$ - razão de umidade predito pelo modelo,

$\mathrm{RU}_{\text {exp }}$ - razão de umidade experimental,

n- número de observações.

\section{RESULTADOS E DISCUSSÃO}

O resumo dos ajustes dos modelos aos dados experimentais das diferentes formulações estão apresentados na Tabela 1. A análise dos parâmetros para a escolha do melhor modelo revela boa representação por todos os modelos aplicados a todas as formulações estudadas os quais são capazes de predizer o comportamento do processo.

Tabela 1. Parâmetros dos modelos matemáticos e seus respectivos coeficientes de determinação $\left(R^{2}\right)$ e desvios quadrados médios (DQM) dos modelos ajustados às curvas de secagem das formulações $n=1,2$ e 3, com espessura da camada de espuma de $1,0 \mathrm{~cm}$, para a temperatura de 70 ㅇ.

\begin{tabular}{|c|c|c|c|c|c|c|c|c|}
\hline \multirow[t]{2}{*}{ Formulação } & \multicolumn{6}{|c|}{ Parâmetros do Modelo de Cavalcanti Mata } & \multirow[t]{2}{*}{$\mathbf{R}^{2}$} & \multirow[t]{2}{*}{ DQM } \\
\hline & $a_{1}$ & b & $a_{2}$ & $a_{3}$ & $\mathbf{a}_{4}$ & $a_{5}$ & & \\
\hline 1 & 0,5195 & $-0,0163$ & 0,9977 & 0,5195 & 0,9977 & $-0,0433$ & 0,997 & 0,0000 \\
\hline 2 & 1,2846 & $-0,0004$ & 1,6818 & $-0,9589$ & 1,1764 & 0,7001 & 0,992 & 0,0004 \\
\hline \multirow[t]{3}{*}{3} & 0,5083 & $-0,0037$ & 1,2505 & 0,5086 & 1,2505 & $-0,0200$ & 0,999 & 0,0000 \\
\hline & \multicolumn{6}{|c|}{ Parâmetros do Modelo Logarítmico } & $\mathbf{R}^{2}$ & DQM \\
\hline & \multicolumn{3}{|c|}{ a } & 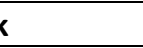 & \multicolumn{2}{|c|}{ c } & & \\
\hline 1 & \multicolumn{2}{|c|}{1,0384} & \multicolumn{2}{|c|}{0,0162} & \multicolumn{2}{|c|}{$-0,0428$} & 0,997 & 0,0000 \\
\hline 2 & \multicolumn{2}{|c|}{1,2314} & \multicolumn{2}{|c|}{0,0098} & \multicolumn{2}{|c|}{$-0,1322$} & 0,967 & 0,0000 \\
\hline \multirow[t]{3}{*}{3} & & 93 & & 109 & & 738 & 0,997 & 0,0000 \\
\hline & \multicolumn{6}{|c|}{ Parâmetros do Modelo de Midilli e Kucuk } & $\mathbf{R}^{2}$ & DQM \\
\hline & \multicolumn{2}{|l|}{ a } & $\mathbf{k}$ & $\mathbf{n}$ & \multicolumn{2}{|r|}{ b } & & \\
\hline 1 & \multicolumn{2}{|c|}{0,9953} & 0,0154 & 1,0241 & \multicolumn{2}{|c|}{$-0,0001$} & 0,997 & 0,0001 \\
\hline 2 & \multicolumn{2}{|c|}{1,0392} & 0,0002 & 1,8348 & \multicolumn{2}{|c|}{$-0,0000$} & 0,992 & 0,0013 \\
\hline \multirow[t]{3}{*}{3} & \multicolumn{2}{|c|}{0,9920} & 0,0034 & 1,2673 & \multicolumn{2}{|c|}{$-0,0000$} & 0,999 & 0,0001 \\
\hline & \multicolumn{6}{|c|}{ Parâmetros do Modelo de Page } & $\mathbf{R}^{2}$ & DQM \\
\hline & \multicolumn{3}{|c|}{$\mathbf{k}$} & \multicolumn{3}{|c|}{$\mathbf{n}$} & & \\
\hline 1 & \multicolumn{3}{|c|}{0,0119} & \multicolumn{3}{|c|}{1,0987} & 0,996 & 0,0018 \\
\hline 2 & \multicolumn{3}{|c|}{0,0002} & \multicolumn{3}{|c|}{1,7973} & 0,991 & 0,0013 \\
\hline 3 & \multicolumn{3}{|c|}{0,0031} & \multicolumn{3}{|c|}{1,3012} & 0,999 & 0,0010 \\
\hline
\end{tabular}

Os coeficientes de determinação $\left(R^{2}\right)$ encontrados para todos os ajustes foram superiores a 0,96 e desvios quadráticos médios inferiores a 0,01. O modelo de Cavalcanti Mata apresentou os maiores coeficientes de determinação e menores desvios quadrático médio para todas as formulações, o que é atribuído ao número de parâmetros de ajustes presentes no modelo. Resultados semelhantemente ao encontrado no estudo é relatado por Carvalho et al. (2007) que 
ao utilizarem o modelo de Cavalcanti Mata, obtiveram $\mathrm{R}^{2}$ igual a 0,9562, ao ajustarem este modelo à curva de secagem da polpa de umbu-cajá adicionada de amido modificado, na temperatura de 70 ․C. Silva et al. (2008) ao estudar a desidratação da polpa de tamarindo pelo método de camada de espuma, ajustou os dados experimentais da secagem aos modelos de Page, Henderson e Pabis e Midilli \& Kucuk, obtendo valores de $\mathrm{R}^{2}$ superiores a 0,96 e DQM inferiores a 0,02, sendo o modelo de Midilli \& Kucuk escolhido para representação da secagem.

Fernandes (2010) ao estudar a secagem em camada de espuma da polpa de cajá integral com adição de três diferentes concentrações do emulsificante Emustab ${ }^{\circledR}$ (1, 2 e 3\%), e uma concentração fixa do aditivo Super Liga Neutra (2\%), destratadas nas temperaturas de 60, 70 e 80 ${ }^{\circ} \mathrm{C}$, obteve para o modelo de Cavalcanti Mata $\mathrm{R}^{2}>0,99$ e $\mathrm{DQM}>0,01$.

O modelo de Cavalcante Mata também foi encontrado como melhor modelo representativo por Melo et al. (2013) ao estudar a secagem em camada de espuma da polpa do fruto do mandacaru, encontrando valores de $R^{2}$ superiores a 0,99 e DQM inferiores a 0,001.

Nas Figuras 2 a 5 estão representadas as cinéticas de secagem das Formulações no 1, 2 e 3, para um tempo de batimento de $5 \mathrm{~min}$, na temperatura de 70 ㅇ C com espessura da camada de espuma de 1,0 cm, na forma adimensional de água (razão de teor de água) em função do tempo de secagem ajustadas aos modelos de Cavalcanti Mata, Logarítmico, Midilli e Kucuk e Page.

Em todas as curvas percebe-se redução gradativa nos tempos de secagem, com perda do teor de agua mais rápida no inicio do processo. Verifica-se ainda que a formulação 1 apresentou uma maior redução do teor de agua comparadas com as demais formulações ate os 120 min.

Verifica-se redução da razão de umidade em função do tempo e que o menor tempo de secagem ocorreu na formulação 1, percebendo -se também que no inicio do processo de secagem a perda de umidade foi maior

A máxima eliminação de água (ponto de equilíbrio) ocorreu aos 120 min para a temperatura avaliada.

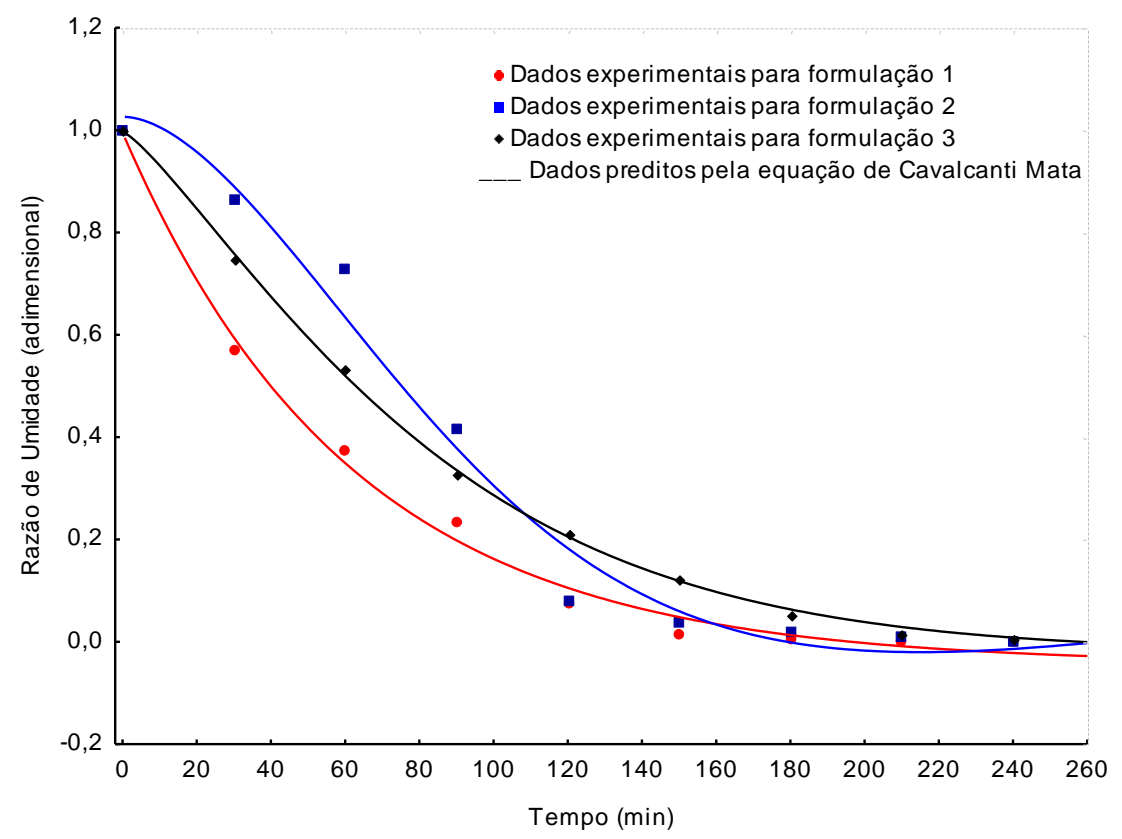

Figura 2. Cinética de secagem das Formulações no 1, 2 e 3 do caqui, na temperatura de 70 C ajustada ao modelo de Cavalcanti Mata. 


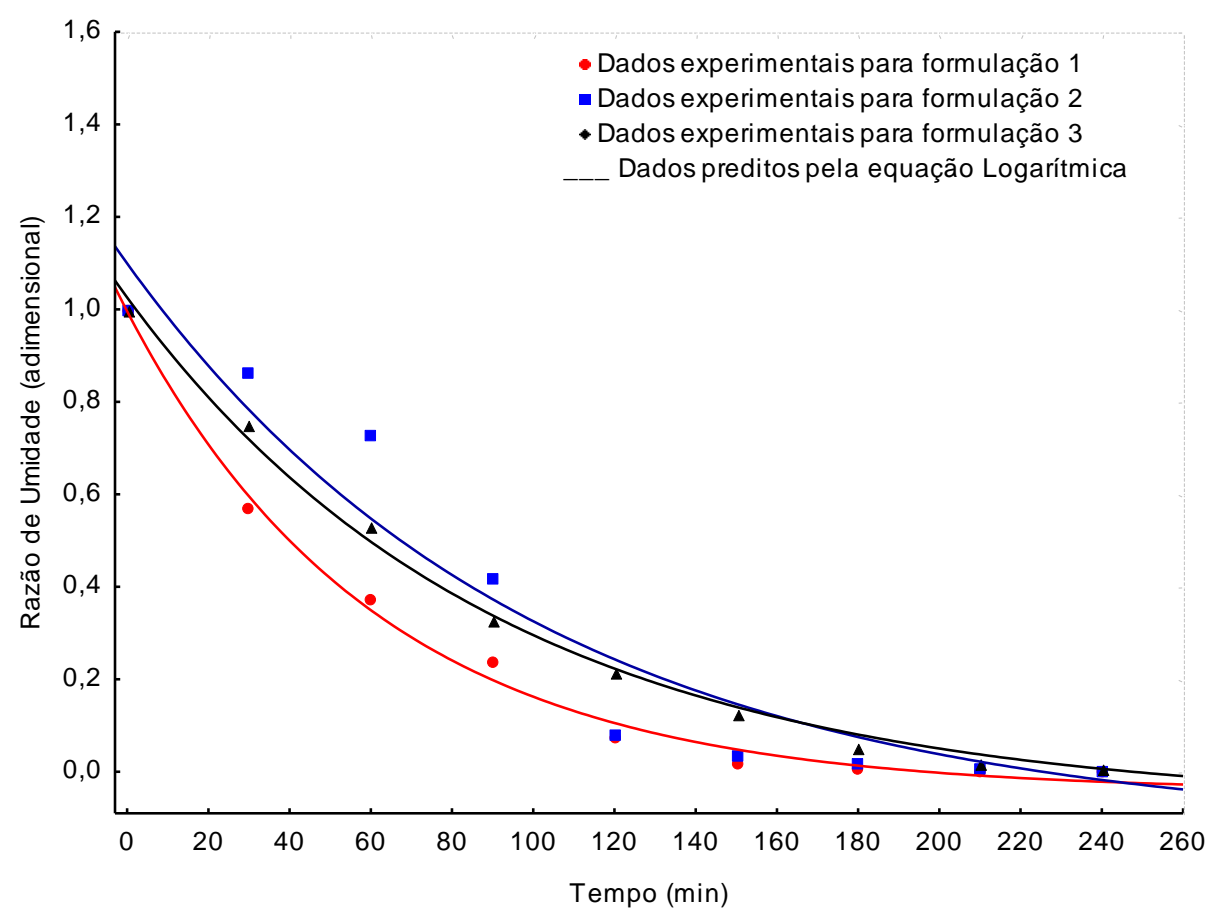

Figura 3. Cinética de secagem das Formulações no 1, 2 e 3 do caqui, na temperatura de 70 ㄷ C ajustada ao modelo de Logarítmico.

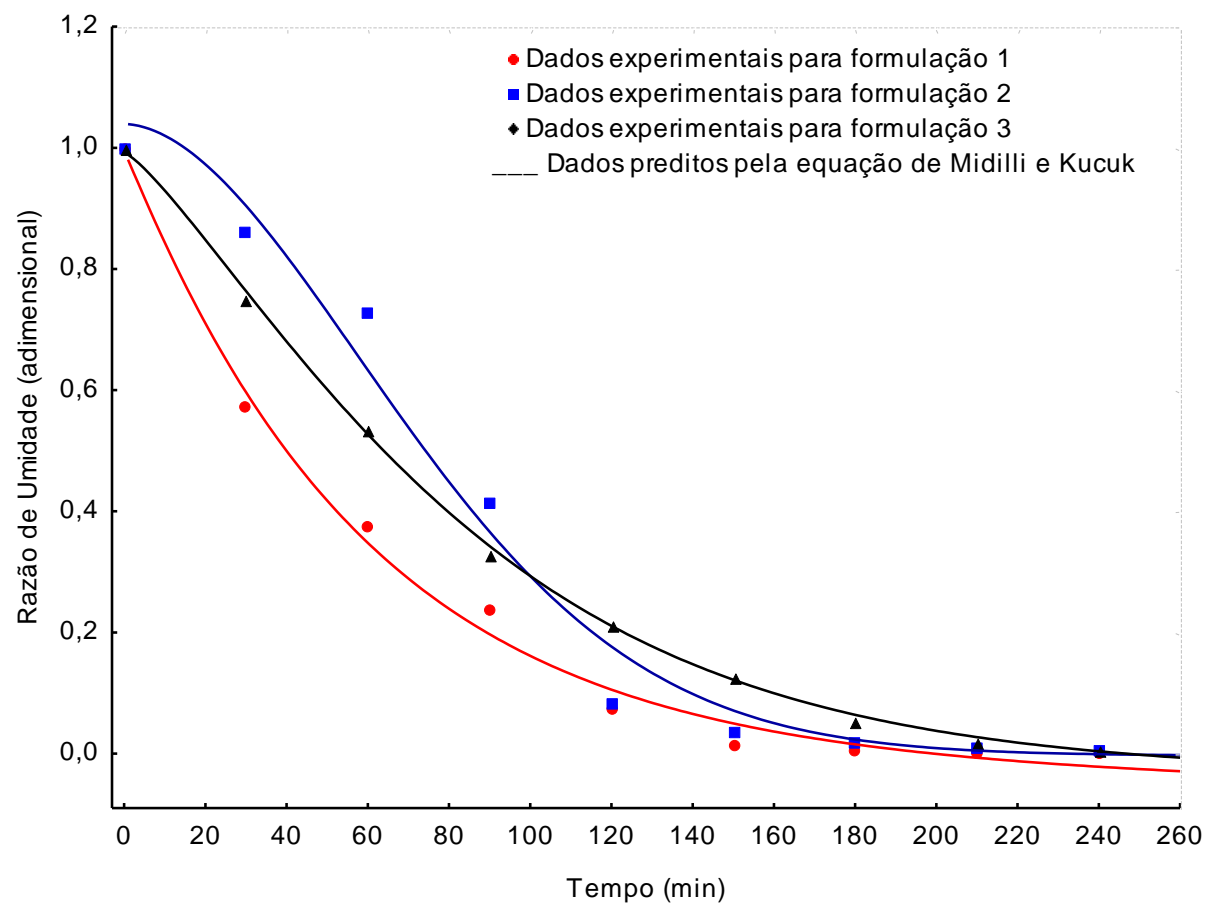

Figura 4. Cinética de secagem das Formulações no 1, 2 e 3 do caqui, na temperatura de 70 C ajustada ao modelo de Midilli e Kucuk. 


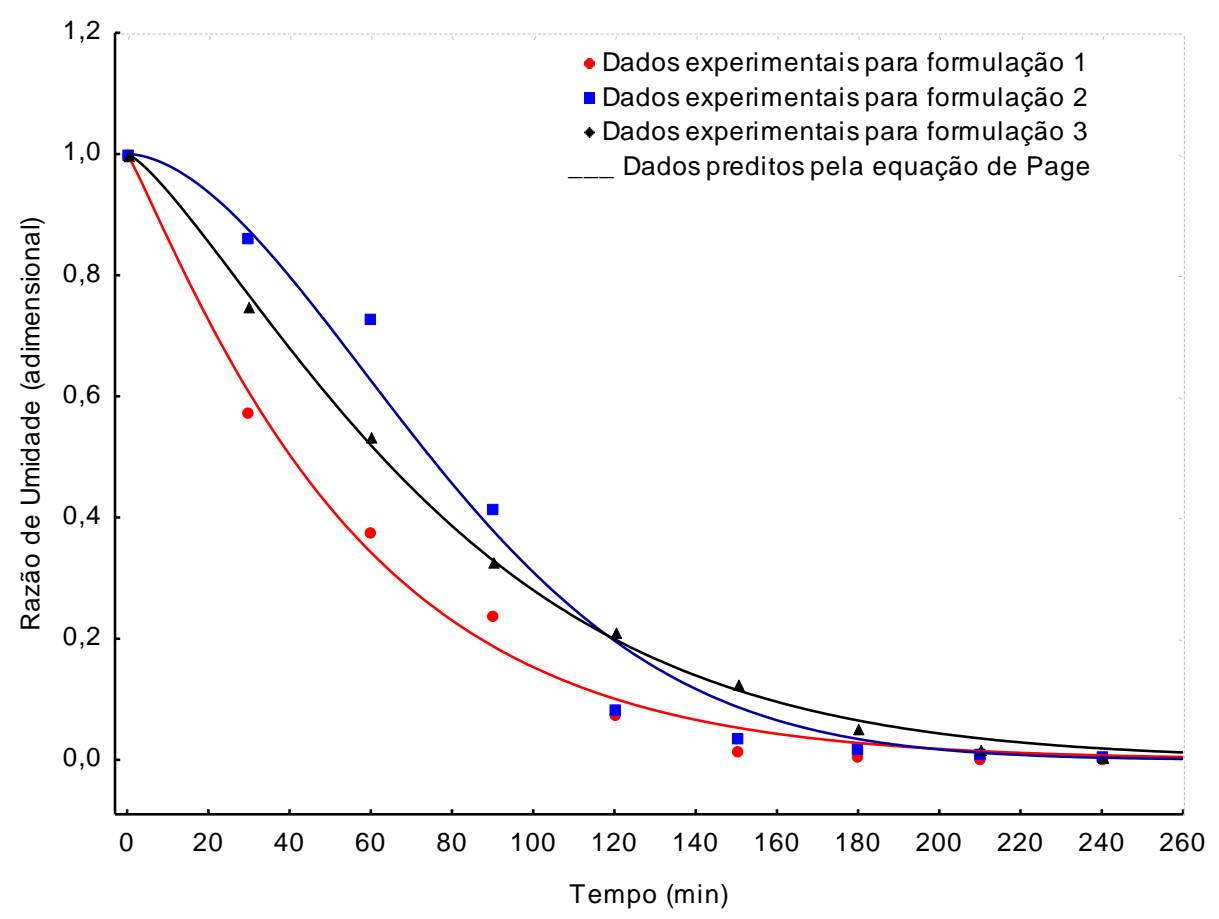

Figura 5. Cinética de secagem das Formulações no 1, 2 e 3 do caqui, na temperatura de 70 oC ajustada ao modelo de Page.

\section{CONCLUSÕES}

A secagem da polpa de caqui em camada de espuma nas diferentes formulações estudadas é representada satisfatoriamente pelos modelos de Cavalcanti Mata, Logaritimico, Midilli e Kucuk e Page, com os melhores ajustes revelados pela equação de Cavalcanti Mata.

Para a polpa de caqui desidratada pelo método foam mat o tempo necessário para atingir o teor de água de equilíbrio foi aos 120 min nas três formulações.

\section{REFERÊNCIAS BIBLIOGRÁFICAS}

1. AKPINAR, E.K. Mathematical modeling of thin layer drying process under open sun of some aromatic plants. Journal of Food Engineering, v.77, n.4, p.864-70, 2006.

2. BASTOS, D. S.; SOARES, D. M. B. G.; ARAUJO, K. G. L; VERRUMA-BERNARDI, M. R. Desidratacao da polpa de manga "tommy atkins" utilizando a tecnica de foam mat drying - avaliacoes quimicas, fisico-quimicas e sensoriais. Braz. Jour. Food Technol., v. 8, n. 4, p.283-290, out./dez. 2005.

3. CARVALHO, C. M.; FIGUEIRÊDO, R. M. F.; QUEIROZ, A. J.; PAIVA, K. M. R.; GONDIM, M. M. S. Secagem da polpa formulada de umbu-cajá. In: Congresso Brasileiro de Engenharia Agrícola, 36., 2007, Bonito. Anais...Bonito: SBEA, 2007. CD

4. CHITARRA, M.I.F.; CHITARRA, A.B. Pós-colheita de frutas e hortaliças: fisiologia e manuseio. 2. ed., Lavras: UFLA, 2005, 785 p.

5. CORRÊA, P.C.; RESENDE, O.; MARTINAZO, A.P.; GONELI, A.L.D.; BOTELHO, F.M. Modelagem matemática para a descrição do processo de secagem do feijão (Phaseolus vulgaris L.) em camadas delgadas. Engenharia Agrícola, Jaboticabal, v.27, n.2, p.501-510, 2007. 
6. COSTA, J. M. C.; MEDEIROS, M. F. D.; MATA, A. L. M. L. Isotermas de adsorcao de pos de beterraba (Beta vulgaris L.), abobora (Cucurbita moschata) e cenoura (Daucus carota) obtidos pelo processo de secagem em leito de jorro: estudo comparativo. Ciencia Agronômica, Fortaleza-CE, v. 34, n. 1, p. 5-9, 2003.

7. FAO. Faostat.Disponível em: <http://www.fao.org>. Acesso em: 27 fev. 2007.

8. FERNANDES, T. K. S. Secagem em camada de espuma da polpa de cajá. 2010. 172 f. (Mestrado em Engenharia Agrícola) - Universidade Federal de Campina Grande, Campina Grande.

9. FORMOSO, V. C.; DAMY, P. C.; TELIS, V. R. N. Secagem por ar quente e degradação de ácido ascórbico em fatias de caqui. XXI Congresso de Iniciação Científica da UNESP, 2009, São José do Rio Preto. Anais. CD-ROM.

10. GONELI, A. L. D.; VIEIRA, M. DO C.; VILHASANTI, H. DA C. B.;GONÇALVES A. A. Modelagem matemática e difusividade efetiva de folhas de aroeira durante a secagem. Pesquisa Agropecuária Tropical, Goiânia, v. 44, n. 1, p. 56-64, jan./mar. 2014.

11. GURJÃO, K. C. O. Desenvolvimento, armazenamento e secagem de tamarindo (Tamarindus indica L.). 2006. 165 f. (Doutorado em Agronomia) - Universidade Federal da Paraíba, Areia.

12. INSTITUTO DE ECONOMIA AGRÍCOLA - IEA. A cultura do caqui em São Paulo. São Paulo, 2005. Disponível em: http://www.iea.sp.gov.br/out/verTexto.php?codTexto=2508. Acesso em: 5 out. 2011.

13. LEMOS, O.L.; JOSÉ, A.R.S.; VILA, M.T.R.; SILVA, K.S.; SILVA, D.S.; BARRETO, A.P.P.; BOMFIM, M.P. Conservação do pimentão 'magali $r$ ' em duas condições de armazenamento associada à atmosfera modificada. Magistra, Cruz das Almas, v.20, n.1, p.6-15, jan./mar. 2008.

14. MELO, K. S. FIGUEIREDO, R. M. F.; QUEIROZ, A. J. M.; FERNANDES, T. K. S.; BEZERRA, M. C. T. Secagem em camada de espuma da polpa do fruto do mandacaru: experimentação e ajustes de modelos matemáticos. Revista Caatinga, v. 26, n. 2, p. 10-17., 2013.

15. RESENDE, O.; CORRÊA, P.C.; GONELI, A.L.D.; BOTELHO, F.M.; RODRIGUES, S. Modelagem matemática do processo de secagem de duas variedades de feijão (Phaseolus vulgaris L.). Revista Brasileira de Produtos Agroindustriais, Campina Grande, v.10, n.1, p.17-26, 2008.

16. SILVA, A. S.; GURJÃO, K. C. O.; ALMEIDA, F. A. C.; BRUNO, L. A.; PEREIRA, W. E. Desidratação de polpa de tamarindo pelo método de camada de espuma. Ciência Agrotécnica, v. 32, n. 6, p. 1899-1905, 2008.

17. SIMÃO, S. Tratado de Fruticultura. Piracicaba: FEALQ, 1998. 760p.

18. TIBOLA, C.S.; FACHINELLO, J.C. Tendências e estratégias de mercado para a fruticultura. Revista Brasileira Agrociência, Pelotas - RS, v.10, n. 2, p. 145-150, abr-jun, 2004.

19. VASCONCELOS, A. R. D. Utilização de cloreto de cálcio e atmosfera modificada na conservação de caqui cv. Fuyu. Lavras, 2000, 85 p. Dissertação (Mestrado em Ciências dos Alimentos, Universidade Federal de Lavras (UFLA).

20. VILELA, P.S. Análise da oferta e demanda de frutas no Brasil para o decênio 2001/2010. Disponívelem:<http://www.faemg.org.br/Content.aspx?Code=348\&ParentCode=13\&Parent Path=None;13\&ContentVersion=C >. Acesso em: 12 set. 2014.

21. WRIGHT, K. P.; KADER, A. A. Effect of slicing and controlled-atmosphere storage on the ascorbate content and quality of strawberries and persimmons. Postharvest Biology and Technology, v. 10, n. 1, p. 39-48, 1997. 